\title{
ATIVIDADE REPRODUTIVA DE PHYSALAEMUS SIGNIFER (ANURA, LEPTODACTYLIDAE) EM AMBIENTE TEMPORÁRIO
}

\author{
Henrique Wogel ${ }^{1}$ \\ Patrícia A. Abrunhosa ${ }^{1}$ \\ José P. Pombal Jr. ${ }^{1}$
}

\begin{abstract}
BREEDING ACTIVITY OF PHYSALAEMUS SIGNIFER (ANURA, LEPTODACTYLIDAE) IN A TEMPORARY POND. The breeding activity of Physalaemus signifer (Girard, 1853) was monitored from July 1999 to July 2000 in a temporary pond in Palmital, Municipality of Saquarema, State of Rio de Janeiro, Atlantic Rain Forest, Brazil. Males were sexually actives only in four nights, arriving at the pond on the early rainy season. Males in amplexus were larger and spent more nights in the reproductive aggregation than solitary ones. The number of nights was correlated with the mass of the males. Males adopted satellite behavior as alternative tactic for mate acquisition. Changes between calling and satellite tactics were observed in different nights. Calling males were not larger and heavier than satellite ones. Satellite behavior seemed to be related with the order of arrival on the pond. Size and mass of males did not influence the results of fights. Resident males won the majority of agonistics combats. Three types of vocalizations are described: advertisement, territorial, and encounter calls.
\end{abstract}

KEYWORDS. Amphibia, Physalaemus, mating success, satellite behavior, agonistic behavior.

\section{INTRODUÇÃO}

Vários estudos sobre seleção sexual em anfíbios anuros mostraram que determinadas características morfológicas e comportamentais, como o comprimento rostro-anal, vocalizações e o número de noites de participação no coro, podem influenciar o sucesso reprodutivo dos machos (FELLERS, 1979; WoODWARD, 1982; RYAN, 1985). Nos últimos 20 anos, diversos estudos têm mostrado que o sistema de acasalamento dos anuros não é aleatório, podendo ser explicado pela competição entre machos (ARAK, 1983) ou por escolha da fêmea (RYAN, 1985).

Fêmeas são consideradas um recurso limitante para o sucesso reprodutivo dos machos nos coros reprodutivos (WELLS, 1977a; RYAN, 1985; ROBERTSON, 1986). Em densas agregações reprodutivas, é comum a observação de interações agressivas entre machos pelas fêmeas (Wells, 1978; Bastos \& Haddad, 1995; Martins et al., 1998), uma vez que vizinhos podem interceptá-las ou causar interferência acústica (HADDAD, 1991; SCHWARTZ,

1. Depto de Vertebrados, Museu Nacional, Universidade Federal do Rio de Janeiro, Quinta da Boa Vista, 20940-040 Rio de Janeiro, RJ, Brasil. (hwogel@acd.ufrj.br) 
1993). Segundo PARKer (1974), a agressão animal, utilizada na defesa de um recurso, deverá ser favorecida pela seleção quando existir menos recursos que competidores, beneficiando o indivíduo que conseguir expulsar vizinhos coespecíficos, obtendo, desta forma, ganhos imediatos em sua aptidão. A maioria dessas interações é resolvida através da emissão de vocalizações e raramente os competidores envolvem-se em combates físicos, a fim de se evitar injúrias ou aumento na vulnerabilidade a predadores (ROBERTSON, 1986; MarTins et al., 1998). Contudo, quando combates físicos ocorrem, o tempo de residência e o tamanho dos machos, ou ambos, são os fatores responsáveis pelo resultado da interação (Howard, 1978; Wells, 1978; Fellers, 1979; KREBS, 1982).

Em resposta à variação intra-específica dos machos em sua capacidade de obter parceiras sexuais, estratégias alternativas de acasalamento podem surgir, favorecendo indivíduos menos aptos (WALTZ, 1982; ARAK, 1983). Estratégia satélite tem sido observada em diversas espécies de anfíbios anuros (PerRil et al., 1978; Forester \& LyKENS, 1986; HADDAD, 1991), na qual machos menores, considerados reprodutivamente inferiores, adotam uma postura submissa e imóvel próximo ao macho dominante (vocalmente ativo e mais atrativo às fêmeas), seja para interceptar fêmeas que se aproximem do macho cantor ou esperar que áreas de corte sejam desocupadas (WeLls, 1977b; HADDAD, 1991).

O gênero Physalaemus Fitzinger, 1826 contém 41 espécies conhecidas e distribuise do México até a Argentina (Frost, 2000). Apesar dessa ampla distribuição, trabalhos de cunho naturalístico baseados em questões da biologia reprodutiva das espécies desse gênero são raros (BoKermanN, 1962; CARdoso, 1981; BARRETO \& ANDRADE, 1995; Brasileiro, 1998; Haddad \& Pombal, 1998; Nascimento et al., 2001; Weber \& Carvalho E SILVA, 2001). Physalaemus pustulosus (Cope, 1864) é uma exceção, pois já foi sujeita a inúmeros estudos, principalmente àqueles ligados à seleção sexual (RYAN, 1985; RYAN \& RAND, 1990; RAND et al., 1992).

Os objetivos, relacionados à biologia reprodutiva de Physalaemus signifer (Girard, 1853), são: determinar se os acasalamentos são aleatórios com relação ao tamanho, massa e número de noites de participação no coro por machos; verificar a existência de estratégias alternativas de acasalamento (comportamento satélite) e como ocorre a manutenção das áreas de corte; descrever o repertório vocal dos machos e avaliar aspectos quantitativos e qualitativos das desovas.

\section{MATERIAL E MÉTODOS}

Espécimes de Physalaemus signifer foram observados em uma pequena poça temporária de, aproximadamente, $170 \mathrm{~m}^{2}$, em borda de mata, na localidade de Palmital, município de Saquarema (22 $50^{\circ}$ 'S, $42^{\circ} 27^{\prime}$ W), Estado do Rio de Janeiro, Brasil, entre julho de 1999 e julho de 2000 . As visitas à área de estudo seguiram-se mensalmente na estação seca e quinzenalmente na estação chuvosa, monitorando-se a poça por 5 a 12 dias consecutivos durante cada visita. O horário das observações no campo transcorreram entre $17 \mathrm{~h}$ até 24h (não considerado o horário de verão), dependendo da atividade dos indivíduos.

Os indivíduos capturados foram medidos com paquímetro de precisão $0,1 \mathrm{~mm}$ para obtenção do comprimento rostro-anal (CRA) e as massas obtidas com uma balança de precisão de $0,05 \mathrm{~g}$. Os indivíduos foram marcados segundo a técnica de amputação de artelhos (MARTOF, 1953). Foi registrado para cada indivíduo o horário de chegada, sua localização na poça e identificados os indivíduos mais próximos. Para a realização das observações comportamentais, foram utilizados os métodos de animal focal, todas as ocorrências e seqüências (LEHNER, 1979). As vocalizações foram gravadas com um gravador UHER 4000 Monitor e microfone UHER M518A em uma velocidade de $19 \mathrm{~cm} / \mathrm{s}$ e um microcassete SONY m-427 em uma velocidade de $2,4 \mathrm{~cm} /$ s. A análise acústica das gravações foi realizada no programa Avisoft-Sonagraph Light versão 2.7. Os parâmetros usados para a caracterização dos cantos foram duração do canto, intervalo entre cantos, número de notas, 
freqüência dominante, estrutura do canto e modulação de freqüência. A terminologia adotada para a descrição do canto segue Heyer et al. (1990). Todos os casais em amplexo foram acondicionados em sacos plásticos com água do local para obtenção da desova; para cada desova foi quantificado o número de ovos. Espécimestestemunho estão depositados na coleção de anfíbios do Museu Nacional, Universidade Federal do Rio de Janeiro, RJ (MNRJ).

A razão sexual operacional (EMLEN \& ORING, 1977) foi obtida dividindo o número de fêmeas pelo número de machos presentes no agregado reprodutivo de cada noite observada. Para a análise estatística dos dados, utilizou-se o teste " $\mathrm{t}$ " de Student e o coeficiente de correlação de Pearson (r) para provas paramétricas e, para provas não-paramétricas, o teste-U de Mann-Whitney e o coeficiente de correlação de Spearman $\left(r_{s}\right)(Z A R, 1984)$. Os dados são apresentados como média \pm desvio padrão e foram considerados significativos com $\mathrm{p} \leq 0,05$.

\section{RESULTADOS}

Atividade do coro. As fêmeas de $P$. signifer (CRA: 27,4 $\pm 1,6 \mathrm{~mm}, \mathrm{n}=7$; massa: $1,52 \pm 0,29 \mathrm{~g}, \mathrm{n}=7)$ foram maiores $(\mathrm{t}=-3,88 ; \mathrm{p}=0,001)$, mas não significativamente mais pesadas depois da oviposição $(\mathrm{t}=-0,54 ; \mathrm{p}=0,59)$ que os machos (CRA: 25,0 $0 \pm 1,0 \mathrm{~mm}$, $\mathrm{n}=10$; massa: $1,46 \pm 0,13 \mathrm{~g}, \mathrm{n}=10$ ).

Machos apresentaram-se acusticamente ativos somente durante quatro noites (4 e 5 de outubro, 14 e 15 de novembro de 1999), no início da estação chuvosa, quando a poça ainda se encontrava vazia, contendo apenas pequenos acúmulos de água separados entre si (aqui chamados de microáreas). Somente nos dias 14 e 15 de novembro, observaram-se casais em amplexo $(n=6)$. A atividade de canto dos machos iniciou às $17 \mathrm{~h}$, apresentando pico de atividade duas e três horas após o início (19 e 20h) e estendeu-se até às $24 \mathrm{~h}$. As fêmeas compareceram aos coros entre duas e seis horas após o início da atividade de vocalização (19-23h). Casais em amplexo foram encontrados somente após três horas do início da atividade de vocalização (fig. 1). O número de machos e de fêmeas no agregado reprodutivo $(\mathrm{r}=0,80 ; \mathrm{p}=0,19 ; \mathrm{n}=4$ noites $)$, assim como o tamanho do agregado reprodutivo e a razão sexual operacional $(\mathrm{r}=0,73 ; \mathrm{p}=0,26 ; \mathrm{n}=4$ noites $)$ de cada noite não foram significativamente correlacionados.

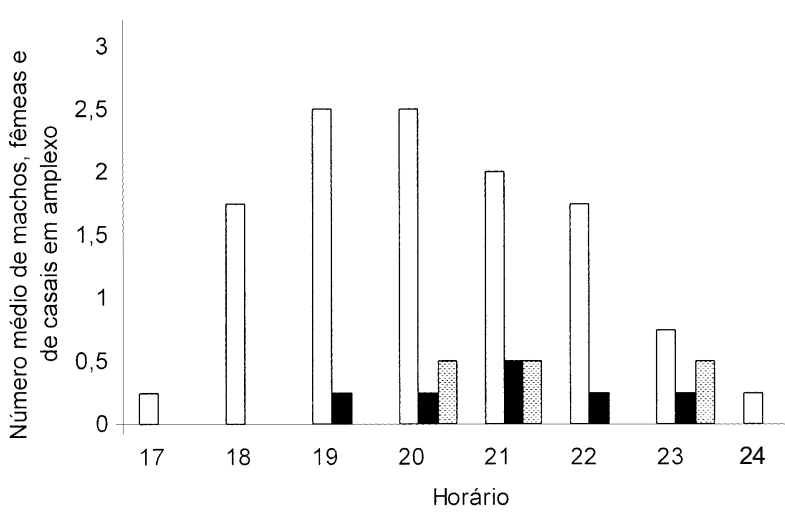

Fig. 1. Distribuição do número médio de machos (colunas brancas), fêmeas (colunas pretas) e casais em amplexo (colunas pontilhadas) ao longo da noite, durante os quatro dias de atividade reprodutiva de Physalaemus signifer, na região de Saquarema, Rio de Janeiro (horário de verão não considerado).
A c a s a lamentos, comportamento satélite e interações agressivas. Machos encontrados em amplexo (CRA: $25,6 \pm 0,5 \mathrm{~mm}, \mathrm{n}=6$; massa: $1,41 \pm 0,10 \mathrm{~g}, \mathrm{n}=6 ; \mathrm{n}^{\circ} \mathrm{de}$ noites: $3,17 \pm 0,75, \mathrm{n}=6$ ) permaneceram por mais noites $(t=2,58 ; \mathrm{p}=0,03)$ em atividade no agregado reprodutivo e foram maiores $(\mathrm{t}=2,43$; $\mathrm{p}=0,03$ ), porém não mais pesados $(\mathrm{t}=-0,13 ; \mathrm{p}=0,89)$ que os machos solitários (machos que não se acasalaram; CRA: $24,5 \pm 1,0 \mathrm{~mm}, \mathrm{n}=6$; massa: $1,42 \pm 0,12 \mathrm{~g}, \mathrm{n}=6 ; \mathrm{n}^{\circ}$ de noites: $1,67 \pm 1,21, n=6)$. 
Houve uma correlação positiva entre o número de noites no agregado reprodutivo e o número de amplexos obtidos, indicando que machos que participaram mais vezes no coro conseguiram mais acasalamentos $(\mathrm{r}=0,62 ; \mathrm{p}=0,05 ; \mathrm{n}=10$ machos). Essa capacidade de permanecer por mais noites correlacionou-se positivamente com a massa dos machos $(\mathrm{r}=0,69 ; \mathrm{p}=0,02 ; \mathrm{n}=10$ machos $)$, mas não com o tamanho ( $\mathrm{r}=0,57 ; \mathrm{p}=0,08 ; \mathrm{n}=10$ machos). Não houve acasalamentos por classe de tamanho de machos e fêmeas em amplexo $(\mathrm{r}=$ $-0,13 ; \mathrm{p}=0,80 ; \mathrm{n}=6$ casais) nem por classe de massa ( $\mathrm{r}=0,75 ; \mathrm{p}=0,08 ; \mathrm{n}=6$ casais).

Machos apresentaram comportamento satélite como estratégia alternativa para aquisição de parceiras sexuais. Machos satélites permaneciam imóveis e próximos aos machos cantores $(\mathrm{x}=7,91 \mathrm{~cm} \pm 2,47 ; \mathrm{n}=11)$, sem emitir qualquer vocalização, porém não em postura que pudesse ser considerada de submissão. Estes indivíduos moviam-se rapidamente em direção a qualquer indivíduo que se aproximasse. Machos cantores (CRA: $25,2 \pm 0,8 \mathrm{~mm}, \mathrm{n}=15$; massa: $1,42 \pm 0,09 \mathrm{~g}, \mathrm{n}=12)$ não foram maiores $(\mathrm{t}=-0,42 ; \mathrm{p}=0,68)$, nem mais pesados $(\mathrm{t}=-1,18 ; \mathrm{p}=0,25)$ que machos satélites (CRA: $25,3 \pm 0,8 \mathrm{~mm}, \mathrm{n}=7$; massa: $1,50 \pm 0,17, \mathrm{n}=4)$.

Em virtude do número reduzido de machos em atividade na poça, foi possível observar os que estavam disponíveis às fêmeas (chamados de grupos), quando estas se aproximavam de uma determinada área de corte (microárea) e quais dos machos obtiveram amplexo (tab. I). Cinco fêmeas aproximaram-se de cinco grupos de machos; quatro grupos eram formados por um par de machos e um grupo por um trio. Dos seis amplexos observados, três foram obtidos por machos cantores e maiores e dois por machos cantores e menores que seus vizinhos. Um macho satélite acasalou-se logo após o macho parasitado e menor ter deixado o local de corte em amplexo (este casal foi capturado, deixando o macho satélite solitário; neste caso, o macho satélite não se tornou cantor).

Em cada microárea onde houve acúmulo de água, observou-se o agrupamento de machos em suas bordas que foram utilizadas como sítio de vocalização. Durante a atividade de vocalização, os machos mantinham a parte posterior do corpo dentro da água $(\mathrm{n}=9)$ ou permaneciam em área úmida adjacente, cerca de $10 \mathrm{~cm}$ de distância da água $(\mathrm{n}=2)$. Todos os satélites ficavam próximos aos cantores, mas sempre fora da água $(\mathrm{n}=11)$. Machos adotaram estratégia cantor quando foram um dos dois primeiros a chegarem à poça $(n=11)$. Dos seis machos que chegaram à poça quando já havia dois vocalizando, cerca de $70 \%$ adotaram estratégia satélite e o restante vocalizou. Destes $70 \%$, metade era menor que o vizinho "parasitado", enquanto a outra metade tinha o mesmo tamanho. Das três vezes em que machos chegaram à poça, quando havia mais de dois machos vocalizando, a estratégia satélite foi adotada. Quatro machos mudaram de estratégia (cantor e satélite) nas noites consecutivas (tab. II).

Tabela I. Grupos de machos disponíveis às fêmeas de Physalaemus signifer (Girard, 1853) em área de corte e respectivas estratégias de acasalamento (CRA, comprimento rostro-anal).

\begin{tabular}{lllll}
\hline Grupos & \multicolumn{2}{l}{ Machos em amplexo } & & \multicolumn{2}{l}{ Machos solitários } \\
& CRA $(\mathrm{mm})$ & Estratégia & CRA $(\mathrm{mm})$ & Estratégia \\
\hline & 25,9 & cantor & 24,6 & \\
2 & 25,0 & cantor & 24,6 & satélite \\
3 & 24,9 & cantor & 26,0 & cantor \\
4 & 24,9 & cantor & 26,0 & cantor \\
5 & 25,9 & cantor & 24,$0 ; 24,6$ & cantor \\
& & & & \\
\hline
\end{tabular}


Tabela II. Estratégias (cantor ou satélite) adotadas pelos machos de Physalaemus signifer (Girard, 1853) segundo a ordem de chegada à poça e o tamanho do macho satélite com relação ao seu vizinho. Em parênteses, o número de vezes que o macho apresentou determinada ordem de chegada $\left(\mathrm{N}, \mathrm{n}^{\circ}\right.$ de identificação; T, tamanho do macho satélite relativo ao seu vizinho cantor).

\begin{tabular}{clll}
\hline Machos & \multicolumn{2}{c}{ Estratégia } & \\
\cline { 2 - 3 } $\mathrm{N}$ & cantor & satélite & $\mathrm{T}$ \\
\hline & primeiro (1) & terceiro (1) & igual \\
2 & primeiro (1) & terceiro (1) & igual \\
& segundo (1) & & \\
& terceiro (1) & & \\
3 & primeiro (1) & quarto (1) & igual \\
& segundo (2) & & \\
8 & segundo (1) & quinto (2) & maior \\
18 & - & terceiro (1) & menor \\
12 & - & terceiro (1) & menor \\
6 & primeiro (1) & - & - \\
& segundo (1) & & \\
17 & terceiro (1) & & - \\
10 & segundo (2) & - & - \\
19 & segundo (1) & - & - \\
\hline
\end{tabular}

Interações agressivas entre machos foram freqüentes durante suas atividades de corte. Essas interações consistiam na emissão de cantos territoriais, cantos de briga e combates físicos entre vizinhos, sejam eles machos cantores ou machos satélites. No total, foram observados 13 combates físicos entre machos, dos quais dois foram entre machos cantores e 11 entre um cantor e um satélite (fig. 2). Antes do combate físico, sempre foram emitidos cantos territoriais pelos machos residentes. Em três ocasiões, após a emissão do canto territorial, foram observados machos satélites se afastando do território do macho cantor, sem que viesse a ocorrer luta. Em outras duas ocasiões, na presença de uma fêmea, machos satélites permaneceram no local após a emissão do canto territorial, não tendo sido observada a luta.

Após emissão do canto territorial, foram observados quatro machos satélites vibrarem todo corpo, incluindo cabeça e membros, por vezes passando as mãos sobre os olhos $(n=2)$; este comportamento foi seguido de luta.

O combate físico era iniciado pelo residente que, após emissão do canto territorial, pulava sobre o intruso $(n=12)$. Somente em uma ocasião, um intruso (satélite) atacou o residente após este ter emitido canto territorial, expulsando-o de seu sítio de canto. No momento da luta, o intruso era abraçado pela região axilar ou inguinal. Por vezes $(n=6)$, o macho agressor (agressor foi definido como aquele macho que iniciava a luta) inflava seu abdômen e levantava a região posterior do corpo esticando suas pernas enquanto abraçava o intruso, geralmente pelas axilas. Os machos agressores emitiam um som de baixa intensidade, antes dos embates físicos ou ao longo dos mesmos, que foi interpretado como canto de briga. Durante o embate, os machos rolavam sobre o substrato e algumas vezes caíam na água $(\mathrm{n}=3)$, onde o residente empurrava o intruso para baixo, mantendoo sob a água. As lutas terminavam somente quando o intruso conseguia escapar do residente. Embora não quantificado, observou-se que a duração das lutas foi bastante variável (um embate de curta duração se estendeu por 6s). Foi possível notar que a resistência de alguns intrusos diante da emissão do canto territorial e combates físicos levava a uma duração crescente do tempo da luta entre estes indivíduos (a uma maior permanência do agressor sobre o intruso). O residente, após o combate físico, retornava ao seu sítio de vocalização, voltando a emitir canto de anúncio $(\mathrm{n}=10)$.

Machos vencedores das lutas (CRA: 25,4 $\pm 0,5 \mathrm{~mm}, \mathrm{n}=13$; massa: $1,48 \pm 0,04 \mathrm{~g}, \mathrm{n}=9$ ) não foram maiores $(U=70,0 ; p=0,44)$ nem mais pesados $(t=-0,66 ; p=0,52)$ que os machos 
INTRUSO CANTOR

INTRUSO SATÉLITE

$(\mathrm{N}=4)$

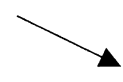

RESIDENTE EMITE

$(\mathrm{N}=6)$

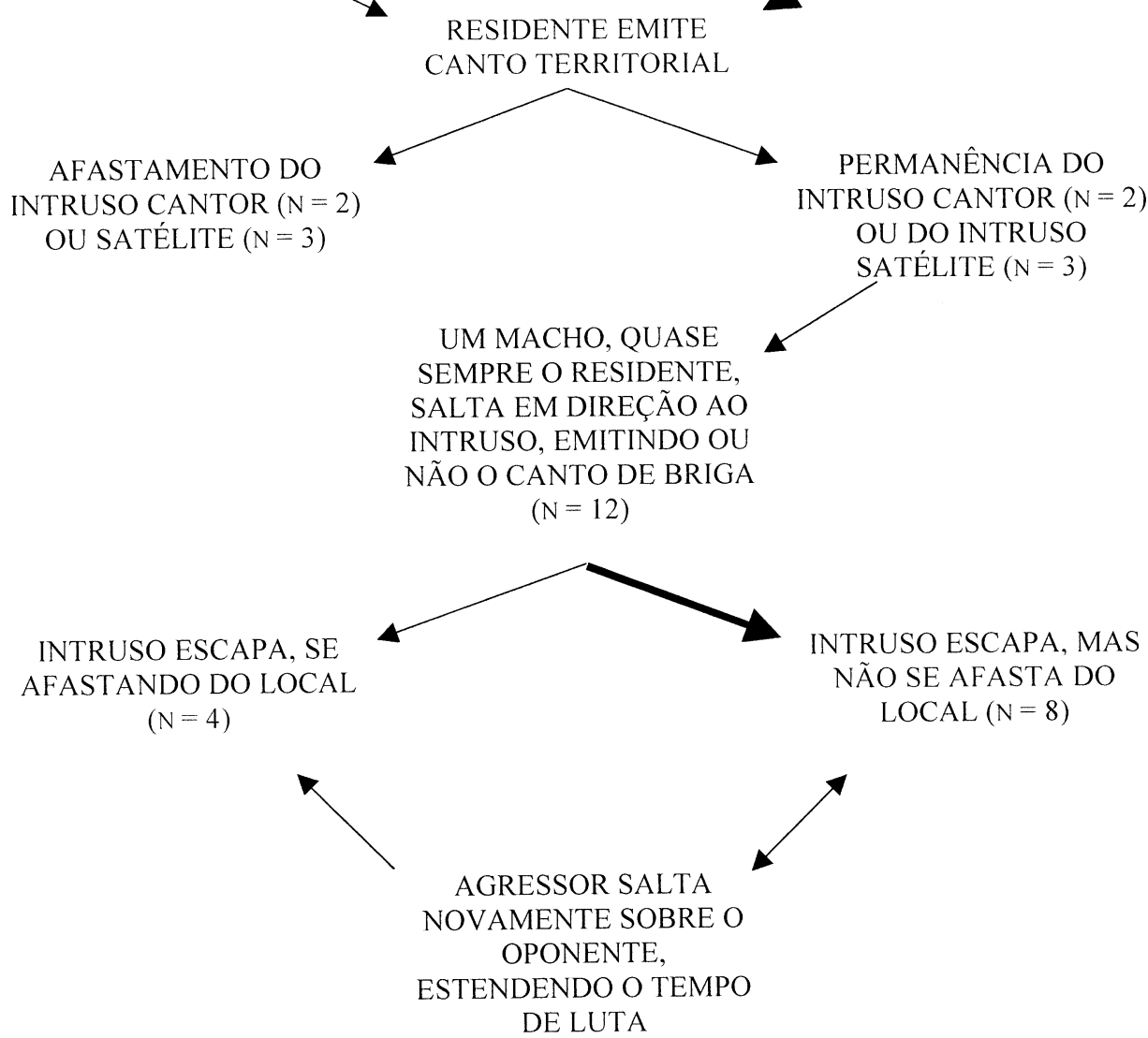

Fig. 2. Seqüência de eventos observados durante as interações agressivas de Physalaemus signifer, Saquarema, Rio de Janeiro (setas espessas correspondem aos eventos mais frequentes).

perdedores (CRA: 25,6 $\pm 0,5 \mathrm{~mm}, \mathrm{n}=13$; massa: 1,51 $\pm 0,14, \mathrm{n}=5$ ). De 13 embates físicos observados, 12 foram vencidos por machos com as seguintes características: cantorresidente-agressor. Apenas um macho vencedor foi um satélite-intruso-agressor. Dentre os perdedores, nove foram satélites-intrusos-agredidos (agredido foi definido como aquele macho que não iniciou uma luta); dois cantores-intrusos-agredidos e dois cantoresresidentes-agredidos. 
Tabela III. Média \pm desvio padrão dos parâmetros acústicos das vocalizações de Physalaemus signifer. O intervalo entre os parênteses equivale à amplitude das medidas tomadas (HM, harmônico e multipulsionado; LA, levemente ascendente; M, multipulsionado).

\begin{tabular}{lccc}
\hline Parâmetros acústicos & $\begin{array}{c}\text { Canto de anúncio } \\
(\mathrm{n}=10)\end{array}$ & $\begin{array}{c}\text { Canto territorial } \\
(\mathrm{n}=3)\end{array}$ & $\begin{array}{c}\text { Canto de briga } \\
(\mathrm{n}=4)\end{array}$ \\
\hline Duração do canto (s) & $\begin{array}{c}0,62 \pm 0,03 \\
(0,60-0,69)\end{array}$ & $\begin{array}{c}1,39 \pm 0,42 \\
(0,91-1,69)\end{array}$ & $\begin{array}{r}1,21 \pm 0,16 \\
(1,02-1,36)\end{array}$ \\
Intervalo entre canto (s) & $\begin{array}{c}0,72 \pm 0,07 \\
(0,66-0,82)\end{array}$ & $\begin{array}{c}0,93 \pm 0,13 \\
(0,84-1,02)\end{array}$ & $\begin{array}{c}1,13 \pm 0,29 \\
(0,94-1,46)\end{array}$ \\
& & & 1 \\
Número de notas & 1 & 0,81 & 1,59 \\
Freqüência dominante Mín. (kHz) & 0,78 & 1,38 & 1,82 \\
Freqüência dominante Máx. (kHz) & 1,64 & HM & M \\
Estrutura do canto & HM & LA no terço & ausente \\
$\begin{array}{l}\text { Modulação de } \\
\text { freqüência }\end{array}$ & $\begin{array}{c}\text { LA na segunda } \\
\text { metade do canto }\end{array}$ & final do canto & \\
\hline
\end{tabular}

Repertório vocal. Durante as interações sociais, machos de P. signifer emitiram três tipos de vocalizações: canto de anúncio (figs. 3, 4), canto territorial (figs. 5, 6) e canto de briga (tab. III; fig. 7). Foram observados machos emitindo o canto de anúncio em antifonia. Quando ocorria sobreposição entre os cantos de dois ou mais machos, os indivíduos retardavam ou aceleravam a taxa de emissão de cantos, ajustando sua repetição de forma a não sobrepor suas vocalizações. O canto territorial (figs. 5, 6) foi emitido sempre que algum intruso, macho cantor ou um satélite, invadia o sítio de vocalização de algum residente. $\mathrm{O}$ canto de briga foi emitido, algumas vezes, pelos agressores, imediatamente antes ou durante as interações agressivas e, em uma outra ocasião, por um macho amplectado quando um macho se aproximou do casal. É um canto de pouca intensidade e de difícil visualização no oscilograma. No sonograma (fig. 7) aparecem três faixas: a central, entre 1,59 e 1,82 kHz, é a freqüência dominante do canto; as demais devem corresponder a "sidebands".

Desovas. A desova de P. signifer consiste em um ninho de espuma depositado em locais extremamente rasos, nas bordas das retenções de água, onde os ovos de coloração esbranquiçada se desenvolvem e os embriões crescem; o desenvolvimento é completado no corpo de água principal. Três desovas foram encontradas (16 de novembro de 1999) sobre o solo, encobertas por folhas secas em local úmido, correspondendo exatamente às bordas das pequenas retenções de água, que haviam se formado com as chuvas nas noites precedentes, quando ocorreram as agregações reprodutivas (14 e 15 de novembro 1999). Pelo fato das chuvas terem cessado, todas as retenções de água secaram e as condições microclimáticas e físicas dos locais das desovas (ambiente apenas úmido) não correspondiam mais às condições locais dos sítios de oviposição (ambiente com água) no momento da deposição dos ovos pelo casal. 

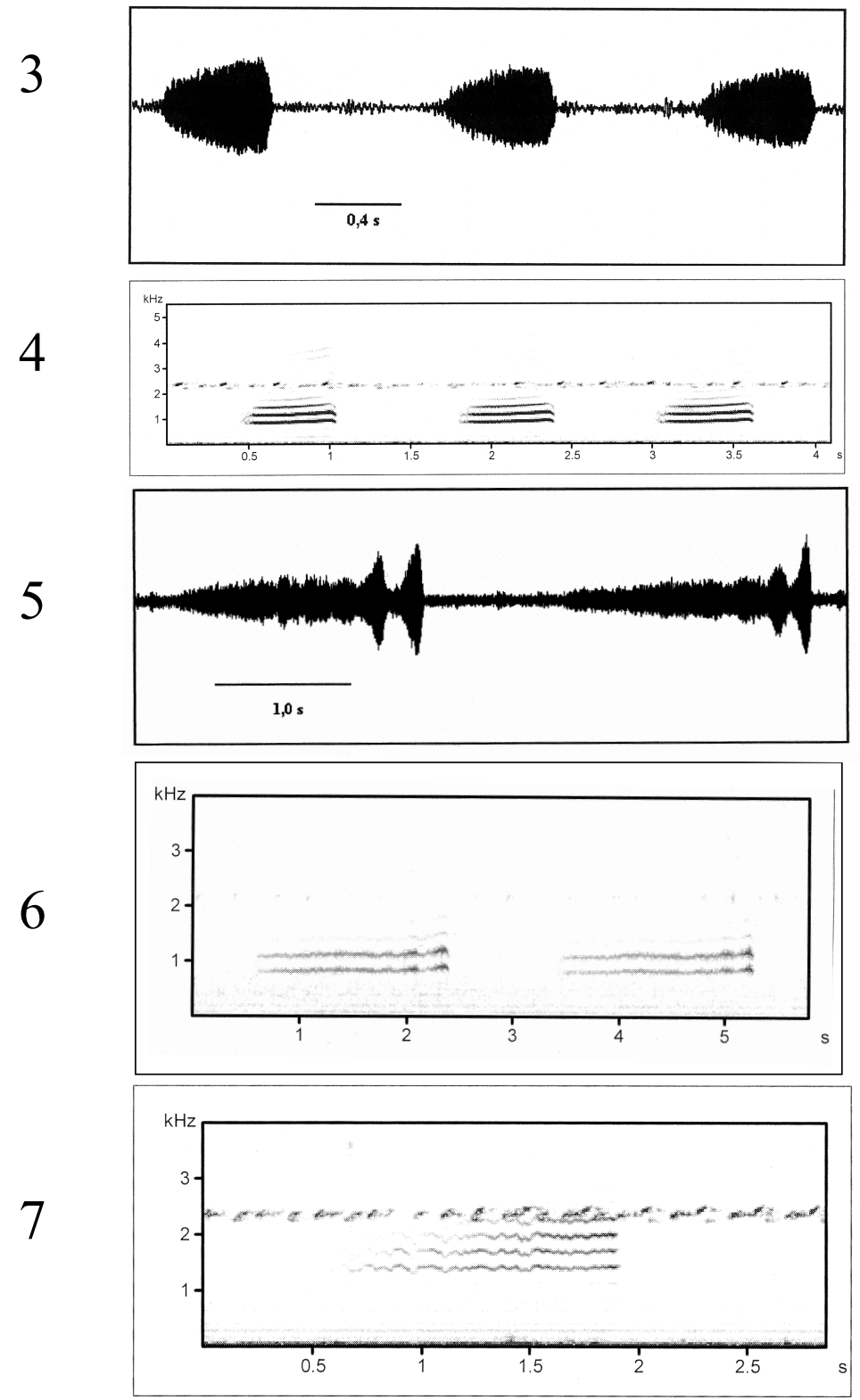

Figs. 3-7. Vocalizações de Physalaemus signifer (Girard, 1853), em Saquarema, Rio de Janeiro (temperatura do ar $16^{\circ} \mathrm{C}$ ). Eixos nos sonogramas correspondem à freqüência $\mathrm{x}$ tempo. Seqüência de três cantos de anúncio: 3, oscilograma, 4, sonograma; seqüência de dois cantos territoriais: 5, oscilograma, 6 , sonograma; 7, sonograma de um canto de briga. A faixa que aparece em $2,3 \mathrm{kHz}$ corresponde ao canto de anúncio de Leptodactylus mystacinus (Burmeister, 1861). 
Seis desovas obtidas em laboratório e uma coletada no campo foram quantificadas. O número de ovos variou de 180 a $369(\mathrm{x}=273,14 \pm 69,46)$ e estava correlacionado positivamente com o tamanho $(\mathrm{r}=0,85 ; \mathrm{p}=0,03 ; \mathrm{n}=6)$ e a massa das fêmeas $(\mathrm{r}=0,89 ; \mathrm{p}=0,02$; $\mathrm{n}=6$ ), indicando que fêmeas maiores e mais pesadas apresentaram maior número de ovos.

\section{DISCUSSÃO}

Apesar desta população de $P$. signifer ter apresentado atividade reprodutiva curta na área de estudo, populações de P. signifer em duas localidades do Rio de Janeiro (região de Baixada, município de Magé e região Serrana, Teresópolis) reproduziram-se de agosto a novembro (Luiz N. Weber, com. pess.). Várias outras espécies do gênero também apresentaram período reprodutivo longo (BOKERMANN, 1962; CARDOSO, 1981; RYAN, 1985; HADDAD \& POMBAL, 1998; HEYER et al., 1990). As chuvas escassas entre outubro e novembro na área de estudo, promoveram o aparecimento dos pequenos acúmulos de água, que não duraram por mais de duas noites, mas que foram suficientes para desencadear a atividade reprodutiva desta espécie. Em dezembro, a poça encheu rapidamente de água em função das fortes chuvas, não tendo sido observada a presença de indivíduos em atividade de vocalização. A curta atividade reprodutiva observada para esta população de $P$. signifer pode estar relacionada à falta de condições adequadas na poça à reprodução em longo prazo. De acordo com o padrão temporal reprodutivo, $P$. signifer pode ser considerada uma espécie pioneira, colonizando a poça no início da estação chuvosa (WeBER \& C. E SiLVA, 2001).

Machos que conseguiram amplexo foram maiores e permaneceram por mais noites em atividade no agregado reprodutivo que machos solitários. Correlações entre sucesso de acasalamento e o número de noites no coro têm sido registradas (WOODWARD, 1982; RYAN, 1985; MuRPHY, 1994a, b). Segundo WOODWARD (1982), permanecer no coro o maior número possível de noites pode aumentar a probabilidade de encontros com fêmeas, independente do tipo de seleção sexual que esteja ocorrendo. Vários estudos também indicam que machos maiores apresentavam vantagem em obter acasalamentos nas agregações reprodutivas (WelLS, 1978; RYAN, 1985; BASTOS \& HADDAD, 1996). Essa vantagem pode ser explicada pela preferência das fêmeas (RYAN, 1985; ROBERTSON, 1986) e/ou na capacidade dos machos maiores em manter vizinhos afastados, pois assim, limita-se o número de competidores nas proximidades (DYSON \& PASSMORE, 1992), possibilitando que o canto de cada macho seja acusticamente distinguível para as fêmeas (RoberTson, 1984). A observação do comportamento territorial entre machos vizinhos, impedindo a aproximação e expulsando machos coespecíficos em P. signifer, corrobora a segunda hipótese.

A análise dos grupos de machos disponíveis às fêmeas indicou que, de um total de seis acasalamentos, três foram obtidos por machos maiores que seus vizinhos e dois por machos menores, onde a característica comum a todos foi a atividade de canto. Machos que alocam mais energia na atividade de vocalização obtêm maiores benefícios (ARAK, 1983) e machos pequenos podem ser considerados bons interceptadores de fêmeas, pois são mais ágeis que os machos grandes e estão mais em alerta (FORESTER \& LYKENS, 1986). De um total de seis acasalamentos, apenas um foi obtido por um macho satélite. A taxa de sucesso reprodutivo observada para machos satélites em $P$. signifer $(16,67 \%)$ foi menor em comparação a outras espécies, como Hyla minuta Peters, 1872 e H. ebraccata Cope, 1874, 38\% (MiYamoto \& CANe, 1980; HADDAD, 1991) e em H. cinerea (Schneider, 1792), 43\% (PERRIL et al., 1978). 
O comportamento satélite é aqui relatado pela primeira vez dentro do grupo de espécies P. signifer. No gênero Physalaemus, esse comportamento havia sido registrado para P. cuvieri Fitzinger, 1826 (BARRETO \& ANDRADE, 1995). Vários autores (PERRIL et al., 1978; ForeSTER \& LYKENS, 1986; HADDAD, 1991) observaram que o comportamento satélite é geralmente adotado por machos pequenos, inferiores reprodutivamente e que permanecem imóveis e em posição submissa próximo aos machos cantores. Neste estudo, machos que adotaram comportamento satélite não satisfizeram a nenhuma dessas características, com exceção da imobilidade e do estado em alerta. De um modo geral, machos satélites, além de não terem adotado uma postura aparentemente submissa, não foram menores, nem menos pesados que machos cantores, e assim, não houve razão para serem considerados inferiores. Tal fato pode ter sido responsável pela grande porcentagem de lutas ocorridas entre machos cantores e satélites (das 13 lutas observadas, $85 \%$ foram entre machos cantores e satélites, enquanto apenas $15 \%$ foram entre cantores), onde machos cantores apresentaram baixo grau de tolerância aos satélites. Tais características apresentadas por esses machos silenciosos, entretanto, assemelham-se à estratégia de busca ativa (WeLLs, 1977a), adotada, porém, por machos de espécies de reprodução explosiva e em alta densidade, o que não se aplica para esta espécie.

WeLLS (1977b) propôs duas hipóteses para explicar o comportamento satélite em anuros: machos satélites estão à espera da vacância de sítios de vocalização e/ou são parasitas sexuais, tentando interceptar fêmeas que se aproximem dos machos cantores. Observações de machos satélites em $P$. signifer, movendo-se em direção a qualquer indivíduo que se aproximasse do macho cantor parasitado e o fato de um satélite ter obtido uma fêmea, após a retirada do macho cantor em amplexo de seu sítio de vocalização, corroboram as duas hipóteses acima.

Machos de P. signifer mudaram de estratégia entre comportamento de cantores e satélites. Essa mudança também foi observada em outras espécies de anuros (Wells, 1977b; PERRIL et al., 1978; HADDAD, 1991). Apesar de não se ter verificado as massas dos indivíduos em noites consecutivas, é possível que as mudanças observadas de cantor para satélite estejam relacionadas à perda de massa (Wells, 1977b; RYAN, 1985). Alternativamente, enquanto ARAK (1983) sugeriu que a mudança entre comportamento satélite e de cantor poderia ser parcialmente explicada por efeitos locais (as mudanças nas estratégias seriam dependentes do grau de atratividade de um dos indivíduos do par, onde o mais atrativo seria o cantor e o menos atrativo adotaria a estratégia satélite), HADDAD (1991) verificou que lutas e disputas através da emissão de cantos de encontro parecem determinar a estratégia cantor ou satélite adotada pelos machos depois dos embates. Neste estudo, nenhum desses dois fatores parece influenciar os machos de $P$. signifer em adotar uma ou outra estratégia. Os resultados mostram uma quarta maneira de se estabelecer quem adotará estratégia cantor ou satélite. O comportamento satélite em $P$. signifer relacionou-se com o número de indivíduos que estavam cantando no momento de chegada na poça, independente do tamanho em relação ao vizinho parasitado sexualmente. De um modo geral, adotavam a estratégia satélite a partir do terceiro macho a comparecer no coro reprodutivo. Quando esses mesmos indivíduos estavam entre os dois primeiros a chegar na poça, adotavam o comportamento de macho cantor. Assim, se um macho pequeno chega em uma área depois de outros machos, isso indicará que este indivíduo deverá adotar a estratégia satélite, pois sendo menor diante de seu vizinho, torna-se menos custoso parasitá-lo sexualmente a competir vocalmente. No entanto, para 
os machos de igual ou maior tamanho que chegaram depois e adotaram a estratégia satélite em vez da estratégia cantor, pode ser que sejam machos que estejam poupando energia como observado em Hyla crucifer Wied-Neuwied, 1838 (Forester \& LyKens, 1986).

Das 13 lutas observadas, 12 foram vencidas por machos residentes independente do tamanho e massa dos combatentes. Wells (1978), Sullivan (1982), Crump (1988), Pombal et al. (1994) e Martins et al. (1998) observaram em Atelopus varius (Lichtenstein \& Martens, 1856) (Bufonidae), Hyla faber Wied-Neuwied, 1821 (Hylidae), Brachycephalus ephippium (Spix, 1824) (Brachycephalidae), Bufo woodhousei Girard, 1854 (Bufonidae) e Rana clamitans Latreille, 1801 (Ranidae), respectivamente, que os machos residentes foram vencedores nos encontros agressivos, independente do tamanho dos machos. De acordo com KREBS (1982), existem três hipóteses para explicar a vitória dos residentes sobre os intrusos nos combates físicos: os residentes podem ser maiores, mais fortes, lutadores mais experientes ou, por outras razões, possuem alta capacidade de manter recursos; os residentes podem ter mais a ganhar em sua área que os intrusos, porque uma familiaridade maior de sua área significa maior conhecimento sobre onde se esconder de predadores ou obter alimento ou, simplesmente por uma convenção arbitrária como “o primeiro a chegar será o vencedor e o último será o perdedor". Para a população aqui estudada, a primeira hipótese pode ser rejeitada porque residentes e intrusos não foram diferentes em tamanho e massa, o que pode torná-los competitivamente semelhantes nos embates físicos. A segunda pode também ser descartada, pois os territórios defendidos foram de curta duração e usados exclusivamente para corte e acasalamento. Alternativamente, pode-se sugerir uma quarta hipótese, onde o primeiro macho a entrar em atividade reprodutiva apresentaria níveis mais elevados de testosterona, acarretando assim maior agressividade com relação aos intrusos (Célio F. B. Haddad, com. pess.).

Vocalização em antifonia é uma estratégia comportamental utilizada por muitos machos, garantindo menor interferência acústica intra-específica (ScHWARTZ, 1994). PASSMORE \& TELFORD (1981) sugerem que esse comportamento pode estar relacionado ao espaçamento entre machos (manutenção de territórios), já que é um meio de reduzir a interferência acústica e, portanto, uma forma de maximizar as chances de atração de fêmeas. Segundo CARDoso \& MARTINS (1987), esse mecanismo comportamental parece estar relacionado à densidade populacional, tendo sido observado somente em espécies que apresentavam muitos indivíduos em atividade de vocalização. Neste estudo, entretanto, $P$. signifer não apresentou qualquer relação entre este tipo de comportamento e densidade populacional. Com apenas dois indivíduos, havia ajuste temporal em seus cantos para não ocorrer sobreposição; e, quando por algum motivo, os cantos se sobrepunham, rapidamente um dos indivíduos estendia um pouco mais a duração do intervalo entre cantos ou dava uma parada repentina, retornando à vocalização em antifonia. A estratégia de vocalização em antifonia somente havia sido registrada dentro do gênero para P. cuvieri, sendo considerada um forte sinal de territorialidade relacionada ao sítio de vocalização junto com as interações agressivas (BARRETO \& ANDRADE, 1995).

Os sítios de vocalização de $P$. signifer apresentaram características semelhantes aos sítios de vocalização de espécies cogenéricas. Machos usavam, como sítios de vocalização, as margens de pequenas retenções de água, formando microbacias e geralmente se posicionavam na água, apenas com a parte posterior do seu corpo. A vocalização em microbacias havia sido registrada para $P$. centralis Bokermann, 1962 por BrASILEIRo (1998) e a utilização de sítios pouco profundos (até $5 \mathrm{~cm}$ de profundidade) e 
o posicionamento semelhante dos machos nestas áreas (apenas com a parte posterior do corpo nas margens das poças) haviam sido observados para P. obtectus Bokermann, 1966 por Bokermann (1966) e P. cuvieri por BARRETO \& ANDRADE (1995).

Dentre os dois novos modos reprodutivos propostos por HADDAD \& PombaL (1998) para $P$. spiniger (Miranda-Ribeiro, 1926), (desova em ninho de espuma em locais úmidos próximos à poça e sobre a água acumulada nas axilas de bromélias, com os girinos completando seu desenvolvimento na poça), a desova em ninho de espuma em locais úmidos pode corresponder ao modo reprodutivo de $P$. signifer, com uma ressalva: considerando que, apesar de ser encontrada em locais úmidos, foi depositada quando ainda existia água naquele local; neste caso, o sítio de oviposição corresponde às bordas dos pequenos acúmulos de água que, devido à falta de chuvas e incidência de raios solares, secaram, tornando-se o local apenas úmido. HADDAD \& POMBAL (1998) relacionam estes dois modos reprodutivos alternativos à imprevisibilidade do ambiente e à desova em ninho de espuma, garantindo a sobrevivência dos ovos. Entretanto, pelo menos as desovas em locais úmidos, poderiam ser consideradas como conseqüência direta da instabilidade climática, que teria modificado as condições dos locais usados como sítio de oviposição, transformando-os em locais úmidos. Estas mudanças nas condições microclimáticas e físicas do sítio de oviposição haviam sido verificadas para $P$. cuvieri por BARRETO \& ANDRADE (1995), que as atribuíram, da mesma forma, à exposição solar e ao fato delas terem sido depositadas em locais extremamente rasos.

As correlações positivas e significativas encontradas entre tamanho da fêmea e número de ovos e massa da fêmea e número de ovos corroboram os resultados que se têm a respeito destas correlações (Duellman \& Trueb, 1986; NAscimento et al., 2001), indicando que fêmeas maiores e mais pesadas possuem maior quantidade de ovos.

Agradecimentos. A Ronaldo Fernandes e Gustavo M. Prado (MNRJ), Célio F. B. Haddad (Universidade Estadual Paulista, Rio Claro) e Rogério P. Bastos (Universidade Federal de Goiás), pela leitura do manuscrito e sugestões; Flávio N. Ramos (Universidade Estadual de Campinas, SP) pela ajuda nos trabalhos de campo; ao CNPq, FAPERJ e Fundação Universitária José Bonifácio pelos auxílios concedidos.

\section{REFERÊNCIAS BIBLIOGRÁFICAS}

AraK, A. 1983. Male-male competition and mate choice in anuran amphibians. In: Batenson, P. ed. Mate Choice. Cambridge, Cambridge Univ. p.181-210.

Barreto, L. \& Andrade, G. V. 1995. Aspects of the reproductive biology of Physalaemus cuvieri (Anura: Leptodactylidae) in northeastern Brazil. Amphibia-Reptilia, Leiden, 16(1):67-76.

Bastos, R. P. \& Haddad, C. F. B. 1995. Vocalizações e interações acústicas de Hyla elegans (Anura, Hylidae) durante a atividade reprodutiva. Naturalia, São Paulo, 20:165-176.

1996. Breeding activity of the neotropical treefrog Hyla elegans (Anura, Hylidae). J. Herpetol., Lawrence, 30(3):355-360.

Bokermann, W. C. A. 1962. Observações biológicas sôbre Physalaemus cuvieri Fitz., 1826 (Amphibia, Salientia). Revta bras. Biol., Rio de Janeiro, 22(4):391-399.

1966. Dos nuevas especies de Physalaemus de Espiritu Santo, Brasil (Amphibia, Leptodactylidae). Physis, Buenos Aires, 26(71):193-202.

Brasileiro, C. A. 1998. Physalaemus centralis (NCN). Male-male combat. Herpetological Review, Lawrence, 29(3):165.

Cardoso, A. J. 1981. Biologia e sobrevivência de Physalaemus cuvieri Fitz., 1826 (Amphibia, Anura), na natureza. Ciênc. Cult., São Paulo, 33(9):1224-1228.

Cardoso, A. J. \& Martins, J. E. 1987. Diversidade de anuros durante o turno de vocalizações, em comunidade neotropical. Papéis Avuls Zool., São Paulo, 36(23):279-285. 
Crump, M. L. 1988. Aggression in harlequin frogs: male-male competition and a possible conflit of interest between the sexes. Anim. Behav., London, 36(4):1064-1077.

Duellman, W. E. \& Trueb, L. 1986. Biology of Amphibians. New York, McGraw-Hill. 670p.

Dyson, M. L. \& PAssmore, N. I. 1992. Inter-male spacing and aggression in African painted reed frogs, Hyperolius marmoratus. Ethology, Berlin, 91:237-247.

EmLen, S. T. \& Oring, L. W. 1977. Ecology, sexual selection, and the evolution of mating systems. Science, Washington, 197:215-223.

Fellers, G. M. 1979. Agression, territoriality, and mating behaviour in North American treefrogs. Anim. Behav., London, 27:107-119.

Forester, D. C. \& LYKENS, D. V. 1986. Significance of satellite males in a population of spring peepers (Hyla crucifer). Copeia, Lawrence, 1986 (3):719-724.

Frost, D. R. ed. 2000. Amphibian Species of the World: an online reference. V2.20. (1 september 2000). New York, The American Museum of Natural History.

Haddad, C. F. B. 1991. Satellite behavior in the neotropical treefrog Hyla minuta. J. Herpetol., Lawrence, 25(2):226-229.

Haddad, C. F. B. \& Pombal, J. P., JR. 1998. Redescription of Physalaemus spiniger (Anura: Leptodactylidae) and description of two new reproductive modes. J. Herpetol., Lawrence, 32(4):557-565.

Heyer, W. R.; Rand, A. S. et al. 1990. Frogs of Boraceia. Arq. Zool., São Paulo, 31:231-410.

Howard, R. D. 1978. The evolution of mating strategies in bullfrogs, Rana catesbiana. Evolution, Lawrence, 32:850-871.

KreBs, J. R. 1982. Territorial defence in the great tit (Parus major): do residents always win? Behav. Ecol. Sociobiol., New York, 11:185-194.

LeHNER, P. N. 1979. Handbook of ethological methods. New York, Garland STPM. 403p.

Martins, M.; Pombal, J. P., JR. \& Haddad, C. F. B. 1998. Escalated aggressive behaviour and facultative parental care in the nest building gladiator frog, Hyla faber. Amphibia-Reptilia, Leiden, 19:65-73.

MartoF, B. S. 1953. Territoriality in the green frog, Rana clamitans. Ecology, Washington, 34:165-174.

Miyamoto, M. M. \& CAne, J. H. 1980. Behavioral observations of noncalling males in Costa Rican Hyla ebraccata. Biotropica, Lawrence, 12(3):225-227.

Murphy, C. G. 1994a. Chorus tenure of male barking treefrogs, Hyla gratiosa. Anim. Behav., London, 48:763-777. . 1994b. Determinants of chorus tenure in barking treefrogs (Hyla gratiosa). Behav. Ecol. Sociobiol., New York, 34:285-294.

Nascimento, L. B.; Carvalho, R. R., JR. et al. 2001. Reprodução e descrição do girino de Physalaemus rupestris Caramaschi, Carcerelli \& Feio, 1991 (Amphibia, Anura, Leptodactylidae). Bolm Mus. nac. Rio de J., Nova Série, Sér. Zool., Rio de Janeiro, 450:1-10.

Parker, G. A. 1974. Assessment strategy and the evolution of fighting behaviour. J. Theor. Biol., New York, 47:223-243.

Passmore, N. I. \& Telford, S. R. 1981. The effect of chorus organization on mate localization in the painted reed frog (Hyperolius marmoratus). Behav. Ecol. Sociobiol., New York, 9:291-293.

Perril, S. A.; Gerhardt, H. C. \& Daniel, R. 1978. Sexual parasitism in the green tree frog (Hyla cinerea). Science, Washington, 200:1179-1180.

Pombal, J. P., JR.; Sazima, I. \& Haddad, C. F. B. 1994. Breeding behavior of the pumpkin toadlet, Brachycephalus ephippium (Brachycephalidae). J. Herpetol., Lawrence, 28(4):516-519.

Rand, A. S; RyAn, M. J. \& WilcZYNSKI, W. 1992. Signal redundancy and receiver permissiveness in acoustic mate recognition by the túngara frog, Physalaemus pustulosus. Amer. Zool., New York, 32:81-90.

RoBERTSON, J. G. M. 1984. Acoustic spacing by breeding males of Uperoleia rugosa (Anura: Leptodactylidae). Z. Tierpsychol., Berlin, 64:283-297.

. 1986. Male territoriality, fighting and assessment of fighting ability in the australian frog, Uperoleia rugosa. Anim. Behav., London, 34:763-772.

Ryan, M. J. 1985. The túngara frog. A study in sexual selection and communication. Chicago, The University of Chicago. 230p.

Ryan, M. J. \& RAND, A. S. 1990. The sensory basis of sexual selection for complex calls in the túngara frog, Physalaemus pustulosus (sexual selection for sensory explotation). Evolution, Lawrence, 44:305-314.

Schwartz, J. J. 1993. Male calling behavior, female discrimination and acoustic interference in the neotropical treefrog Hyla microcephala under realistic acoustic conditions. Behav. Ecol. Sociobiol., New York, 32:401-414. 
- 1994. Male advertisement and female choice in frogs: recent findings and new approaches to the study of communication in a dynamic acoustic environment. Amer. Zool., New York, 34:616-624.

Sullivan, B. K. 1982. Sexual selection in woodhouse's toad (Bufo woodhousei) I. Chorus organization. Anim. Behav., London, 30(3):680-686.

Vielliard, J. 1993. "Side-bands" artefact and digital sound processing. Bioacoustics, Oxford, 5:159-162.

WALTZ, E. C. 1982. Alternative mating tactics and the law of diminishing returns: the satellite threshold model.

Behav. Ecol. Sociobiol., New York, 10(2):75-83.

Weber, L. N. \& Carvalho e Silva, S. P. 2001. Descrição da larva de Physalaemus signifer (Girard, 1853) (Amphibia, Anura, Leptodactylidae) e informações sobre a reprodução e a distribuição geográfica da espécie. Bolm Mus. nac. Rio de J., Nova Série, Sér. Zoologia, Rio de Janeiro, 462:1-6.

Wells, K. D. 1977a. The social behaviour of anuran amphibians. Anim. Behav., London, 25(3):666-693. . 1977b. Territoriality and male mating success in the green frog (Rana clamitans). Ecology, Washington, 58(4):750-762.

. 1978. Territoriality in the green frog (Rana clamitans): vocalizations and agonistic interactions. Anim. Behav., London, 26:1051-1063.

Woodward, B. 1982. Male persistence and mating success in woodhouse's toad (Bufo woodhousei). Ecology, Washington, 63(2):583-585.

ZAR, J. H. 1984. Biostatistical Analysis. 2. ed. Prentice-Hall, Englewood Cliffs. 718p.

Recebido em 02.10.2001; aceito em 17.04.2002.

Iheringia, Sér. Zool., Porto Alegre, 92(2):57-70, 30 de junho 2002 